\title{
RASPRAVE I ČLANCI
}

Dr MOMČILO PAVLOVIĆ, naučni savetnik

Dr SRĐAN CVETKOVIĆ, naučni saradnik

Institut za savremenu istoriju

Beograd, Trg Nikole Pašića $11 \quad$ UDK 341.322.5:061.1(497.11)"2009/2012"

\section{ISTRAŽIVANJA DRŽAVNE KOMISIJE ZA TAJNE GROBNICE UBIJENIH POSLE 12. SEPTEMBRA 1944.*}

\begin{abstract}
APSTRAKT: $U$ radu su dati presek $i$ analiza rezultata dosadašnjih istraživanja Državne komisije za tajne grobnice koji se tiču popisa lica i istraživanja lokacija tajnih grobnica. Donosi se presek političke, nacionalne, polne, starosne i socijalne strukture gotovo 37.000 stradalih $i$ nestalih lica evidentiranih do 6. decembra 2012.
\end{abstract}

Ključne reči: Državna komisija, represija, žrtve, struktura stradalih, tajne grobnice

Posle inicijative koju su pokrenuli Institut za savremenu istoriju i list Večernje novosti u akciji Otkopavanje istine, Vlada Republike Srbije donela je na sednici 9. jula 2009. Odluku o osnivanju Državne komisije za pronalaženje i obeležavanje svih tajnih grobnica u kojima se nalaze posmrtni ostaci streljanih posle oslobođenja 1944 (skraćeno: Državna komisija za tajne grobnice ubijenih posle septembra 1944). Komisija je konstuisana na sednici održanoj 12. novembra 2009. Državnu komisiju za tajne grobnice ubijenih posle 12. septembra 1944. čine predstavnici državnih institucija, naučnih ustanova i stručnjaci iz različitih oblasti. Predsednik Komisije je dr Slobodan Marković, docent na Fakultetu političkih nauka u Beogradu, a sekretar dr Srđan Cvetković, naučni saradnik u Institutu za savremenu istoriju. Koordinator Odbora za istraživanje je prof. dr Momčilo Pavlović, direktor Instituta za savremenu istoriju, gde je ujedno i baza istraživanja.

Cilj Komisije jeste da istraži i obeleži sve tajne grobnice u kojima se nalaze posmrtni ostaci lica streljanih posle septembra 1944. Bilo je, takođe,

* Rad je deo projekta Srpsko društvo u jugoslovenskoj državi u 20. veku: između demokratije i diktature (177016), koji finansira Ministarstvo prosvete, nauke i tehnološkog razvoja Republike Srbije. 
potrebno utvrditi tačan broj streljanih lica posle septembra 1944. i o tome dostavljati posebne izveštaje Vladi Srbije. U okviru Komisije formiran je i Odbor za istraživanje i evidentiranje tajnih grobnica, sa zadatkom da istraži i prikupi svu dostupnu dokumentaciju u vezi sa pitanjem stradanja lica posle 1944. Vlada Republike Srbije je na sednici 29. aprila 2010. donela Odluku o skidanju oznaka tajnosti sa dokumenata iz nadležnosti Vlade, koje se odnose na činjenice kada, gde, kako i koliko je lica pobijeno na teritoriji Srbije posle 12. septembra 1944. Odmah na početku Komisija se suočila sa dva velika problema. U građi BIA predatoj Arhivu Srbije nedostajali su spiskovi streljanih za 40\% okruga u Srbiji, uključujući velike gradove Beograd, Kragujevac, Šabac, Novi Sad; istraživači su stoga bili prinuđeni da se upuste u traganje i dopunu podatka iz alternativnih arhivskih izvora. Drugi problem je bio finansijske prirode: nedostajala su sredstva za angažovanje većeg broja istraživača u arhivima, za terenska istraživanja i, naročito, za ekshumacije koje zahtevaju veće materijalne troškove. Dodatno, za ekshumacije žrtava i obeležavanja lokacija nedostajalo je i veće političke volje kao i volje sudova da se upuste u skupe i osetljive postupke.

\section{Popis stradalih i nestalih lica ${ }^{1}$}

Angažovanjem većeg broja saradnika i volontera iz cele Srbije i zahvaljujući finansijskoj pomoći Ministarstva pravde Republike Srbije, Komisija za tajne grobnice je za tri godine rada ipak uspela da prikupi podatke za gotovo 40.000 lica stradalih u posleratnim čistkama na 211 evidentiranih lokacija. Dopuna i sređivanje tog spiska zahtevaju dalji rad, budući da postoje određena ponavljanja i preklapanja. Komisiji je, uz to, ustupljena baza od oko 27.000 stradalih lica, koju je već popisao Anketni odbor Skupštine Vojvodine (2003-2008). Ta baza se trenutno obrađuje, a u narednom periodu treba da bude usavršena i inkorporirana $u$ jedinstvenu bazu podataka, dostupnu građanima preko veb sajta Komisije za tajne grobnice. Podaci o žrtvama preuzeti su najvećim delom iz Arhiva Srbije to jest građe BIA, Arhiva Jugoslavije, lokalnih arhiva: Zaječar, Smederevska Palanka, Smederevo, Čačak, a za teritoriju Vojvodine najviše iz Pokrajinskog arhiva Vojvodine.

\section{Otvorena knjiga žrtava}

Početkom novembra 2011. započeo je i projekat izrade baze podataka koja bi u modernoj i efikasnoj formi predstavila široj javnosti, zainteresovanim licima i institucijama podatke do kojih je došla Komisija. U proje-

${ }^{1}$ Presek je učinjen na osnovu podataka iz internet baze žrtva Otvorena knjiga Državne komisije za tajne grobnice na dan 6. decembra 2012. 
kat Otvorena knjiga žrtava uključeno je pet istraživača i koordinator čiji je zadatak da u ovu formu unesu imena više desetina hiljada žrtava. Izabrani format podržava priloge sa fotografijama, dokumentima i omogućava izradu brze i kvalitetne statistike stradanja po različitim kategorijama. Do 6 . decembra 2012. u ovu savremenu formu uneto je 36.761 ime. Otvorena knjiga žrtva je sadržajna i moderna baza podataka dostupna građanima preko sajta Komisije, u koju svakodnevno mogu imati uvid i koristiti podatke za potrebe rehabilitacije i ostvarivanje drugih prava. Za svako lice u bazi podataka postoji ime i prezime, zanimanje, nacionalnost, prebivalište, mesto rođenja kao i vreme i mesto stradanja, dok se za pojedinačnim lokacijama još uvek traga. Ono što je zanimljivo i što ovaj portal čini interesantnim jeste mogućnost da se klikom na dugme izbace statistički izveštaji. U bazi se mogu pronaći vrlo zanimljivi izveštaji na osnovu do sada obrađenih podataka. Registar žrtava grafički predstavlja broj ubijenih, osuđenih na smrt, umrlih u logoru, nestalih. Podaci pokazuju koliko je pripadnika koje nacionalnosti stradalo, pod kojom kvalifikacijom ili pripadnošću određenim formacijama u ratu i koje su bile starosne dobi.

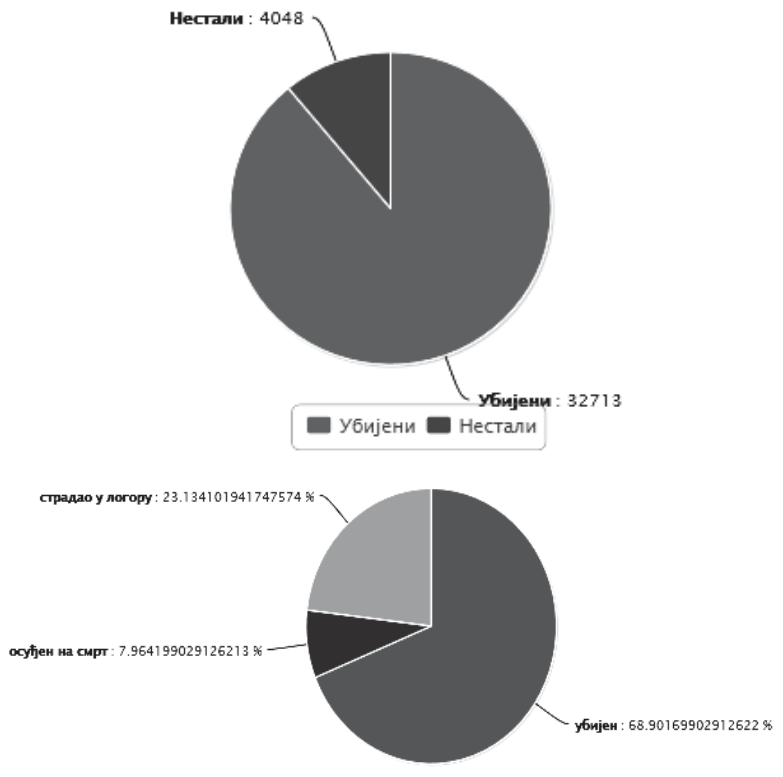

Broj i struktura ubijenih i nestalih posle 12. septembra 1944.

Izvor: Elektronska baza žrtava Državne komisije za tajne grobnice ubijenih posle 12. septembra 1944. 
Prema dosadašnjim podacima, koji nisu i konačni, svega oko 2.500 lica sudski je osuđeno na smrt dok su svi ostali vansudski likvidirani ili stradali u logoru. Ukupno je - imajući u vidu dosadašnje podatke - 71\% žrtava streljano bez suda, $8 \%$ osuđeno na smrt, $20 \%$ stradalo u logoru. Prema nacionalnosti najviše je stradalo Srba, Nemaca, Mađara, Albanaca, Hrvata pa zatim i ostalih.

\section{НАЦИОНАЛНА СТРУКТУРА ЖРТАВА}

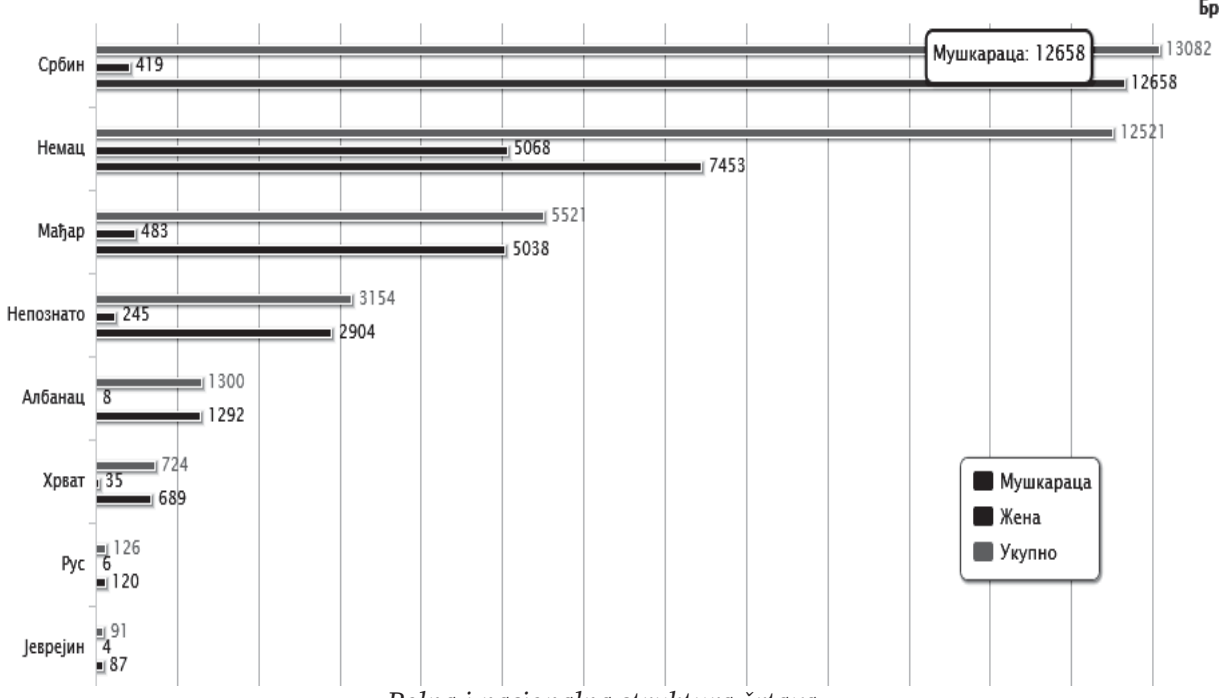

Polna i nacionalna struktura žrtava

(najzastupljenije nacije)

Izvor: Elektronska baza žrtava Državne komisije za tajne grobnice ubijenih posle 12. septembra 1944.

Po političkoj strukturi najviše je civila kolaboranata i narodnih neprijatelja, zatim pripadnika, simpatizera i saradnika JVuO, saradnika i pripadnika albanskih i bošnjačkih milicija na teritoriji centralne Srbije, dok su u Vojvodini najbrojniji nemački i mađarski civili optuženi za kolaboraciju i učešće u okupacionim formacijama ali i znatan broj narodnih neprijatelja Srba. 


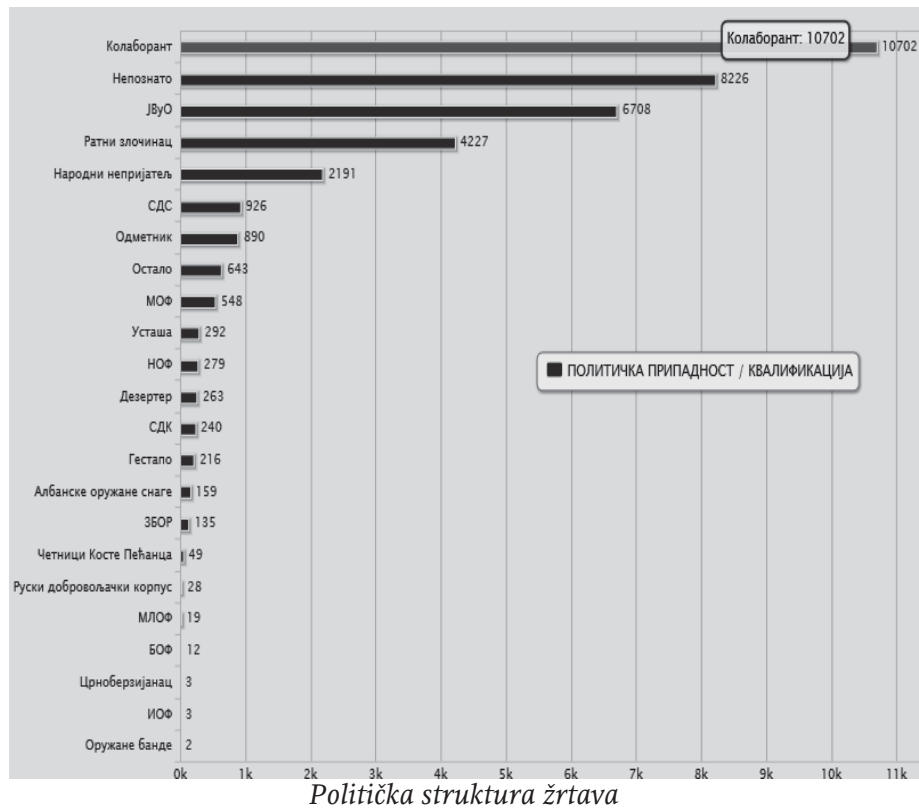

Izvor: Elektronska baza žrtava Državne komisije za tajne grobnice ubijenih posle 12. septembra 1944.

Naročito su interesantni podaci o tome ko su stradali prema zanimanju i socijalnoj strukturi. Prema broju stradalih u odnosu na zastupljenost $u$ društvenoj strukturi izuzetno prednjače: zanatlije (2.086), trgovci kafedžije (776), domaćice (2.198), žandarmi (1.568), advokati i sudije (112), činovnici (940), učenici i studenti (397), učitelji profesori, inženjeri (326), seoski kmetovi/predsednici opština i načelnici (255), oficiri (810), sveštenici (126), industrijalci i preduzetnici (147), glumci/umetnici (70), radnici (714), lekari i apotekari (93), novinari (70). U apsolutnom smislu, razumljivo, najviše je zemljoradnika - više od 8.000, i to mahom imućnijih domaćina. 


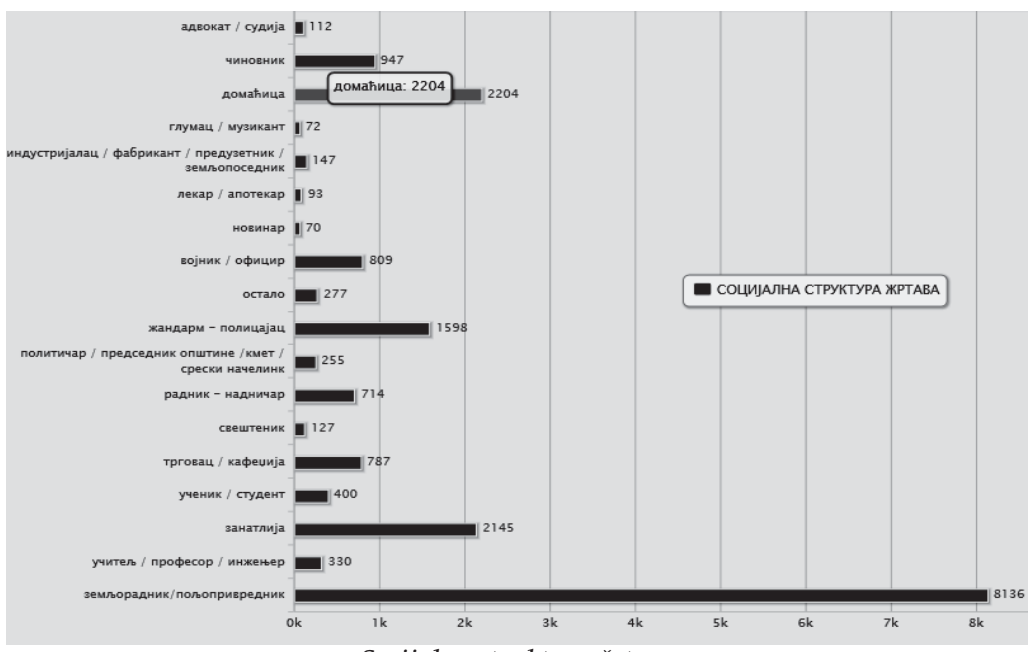

Socijalna struktura žrtava

Izvor: Elektronska baza žrtava Državne komisije za tajne grobnice ubijenih posle 12. septembra 1944.

Među stradalima je mnogo dece, čak više od $8 \%$, izuzetno veliki broj žena kao i staraca od preko 66 godina. To je pre svega posledica velike smrtnosti civila u logorima u Vojvodini, pogotovo najmanje otporne populacije na klimatske i ostale surove logoraške uslove.

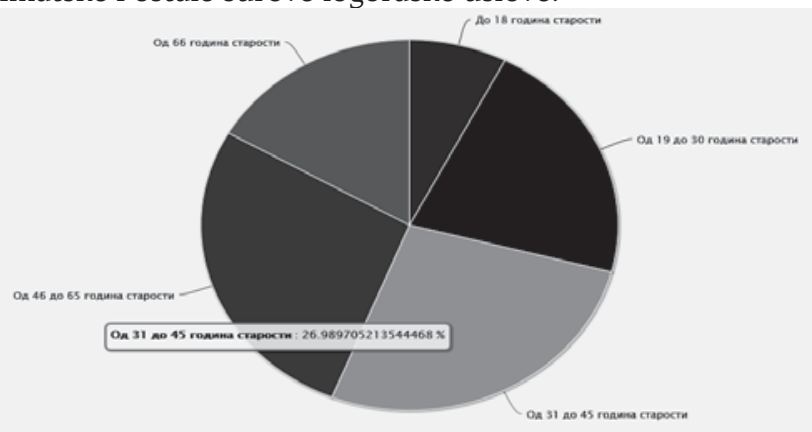

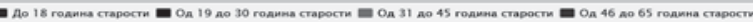

- OA 66 romena crapoer

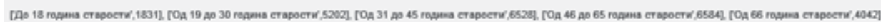
Starosna struktura žrtava 
U okviru Komisije formiran je i Dokumentacioni centar žrtava. Prikupljaju se i arhiviraju dokumenti, fotografije, audio i video zapisi od građana i potomaka. Preliminaran popis žrtava, prema dosadašnjem tempu rada, mogao bi da bude završen najkasnije do kraja 2013. godine. Očekivanje je da broj ubijenih i nestalih posle 12. septembra 1944. dosegne brojku od oko 60.000 žrtava. Postoji plan da se na kraju posla tokom 2013. u saradnji sa Istorijskim muzejem Srbije organizuje izložba posvećena žrtvama posleratnih likvidacija kao i političkoj represiji u tom periodu.

\section{Lokacije tajnih grobnica}

Do kraja 2012. evidentirano je, na osnovu prijava građana i svedoka, 211 lokacija tajnih grobnica. Snimljene su i do sada detaljnije istražene 33 lokacije i saslušano na desetine svedoka u Zaječarskom, Raškom, Valjevskom, Šumadijskom, Mačvanskom okrugu, Beogradu kao i u Severnobačkom okrugu u Vojvodini. Najveći problem za efikasniji i brži rad jesu organizaciono-tehnička sredstva i finansijska podrška za putovanja, što znatno usporava dalja istraživanja (naročito terenski rad), snimanja lokacija i razgovore sa svedocima van Beograda.

Ogroman problem u određivanju lokacija tajnih grobnica jeste dug protok vremena i pozno životno doba svedoka ili nedostatak svedoka iz prve ruke. Često se radi o potomcima i izvorima iz druge ruke koji su nedovoljno precizni, dok se u dokumentima gotovo nikada ne navode tačno lokacije egzekucija. U slučaju da se navode, praktično je nemoguće pronaći lokalitet bez detaljne mape ili svedoka koji može da tačno odredi lokaciju.

\section{Ekshumirane tajne grobnice}

Do sada su izvršene samo četiri probne ekshumacije, koje su u dva slučaja bile pozitivne (Potok Zmijanac - Boljevac i Guvnište kod Vlasotinca). Pred Odborom za istraživanje su dalja ispitivanja lokacija, sondiranje terena i, u određenim slučajevima, ekshumacije.

Tokom prošle godine ekshumirane su dve lokacije tajnih grobnica: potok Zmijanac kod Boljevca i tajna grobnica u krugu Fiata (Zastava) u Kragujevcu.

POTOK ZMIJANAC: Lokaciju tajne grobnice Potok Zmijanac otkrili su 30. septembra 2010. istraživači Državne komisije. Zvanična ekshumacija otpočela je 14. jula 2011. u organizaciji Višeg suda u Zaječaru i sudije Milenka Stanojevića. Ekshumacija je poverena Institutu za sudsku medicinu u Nišu. Iz jedne od dve jame u Potoku Zmijanac kod Boljevca ekshumirano je od strane Višeg suda u Zaječaru i kompletirano 26 tela uz nekom- 
pletne ostatke nekoliko drugih. Očekujemo da će istražni sudija uskoro naložiti ekshumiranje i druge jame sa posmrtnim ostacima žrtava. Reč je o civilima - narodnim neprijateljima iz Boljevca i okolnih sela koje su u periodu od 16. do 18. novembra 1944. pobili pripadnici OZN-e i komunističkog režima, a za koje Državna komisija ima potpuna saznanja i lične podatke na osnovu izjava svedoka i arhivskih istraživanja. Dana 22. oktobra 2010. u organizaciji Opštine Boljevac i uz saradnju sa Državnom komisijom organizovana je sahrana ekshumiranih ostataka u zajedničku grobnicu.

FIAT ZASTAVA: Istražni sudija Višeg suda u Kragujevcu Zorica Đurić obavestila je 9. decembra 2011. Državnu komisiju za tajne grobnice da je posle više nalaza ljudskih kostiju na lokaciji kod parkinga zgrade Energetike odlučila da obustavi građevinske radove jer ,ljudski i moralni razlozi nalažu da se prema ljudskim ostacima odnosimo na civilizovan način“. Istragu je poverila stručnjacima Instituta za sudsku medicinu iz Beograda. Sudija Đurić je konsultovala Državnu komisiju o iskustvima oko procedure ekshumacije tajnih grobnica iz vremena s kraja Drugog svetskog rata i interesovala se kakva su bila iskustva prilikom ekshumacije tajne grobnice Potok Zmijanac u Boljevcu.

$\mathrm{Na}$ osnovu dosadašnjih nalaza utvrđeno je prisustvo više desetina skeleta i pojedinačnih ostataka na lokaciji parkirališta kod nekadašnje zgrade Energetike, na samom kraju fabričkog kruga Fiata. Veličina grobnice iznosi 10 x 15 metara. Postoji osnovana sumnja da se radi o tajnoj grobnici nastaloj posle Drugog svetskog rata na prostoru gde su narodne neprijatelje streljale revolucionarne komunističke vlasti. Tu sumnju dodatno potvrđuje činjenica da je posle uklanjanja sloja zemlje u dubini od jedan metar istraživački tim Instituta za sudsku medicinu, kojim rukovode iskusni antropolog dr Marija Đurić i arheolog Andrej Starović, otkrio gomilu nedogorelih sveća. Od pojedinih svedoka se saznalo da su se ovde godinama posle rata okupljali potomci streljanih i palili sveće za pokojnike. Činjenica da je na tom mestu nastao parking upravo preko jame za koju se već znalo, dodatno potvrđuje sumnju da se radi o grobnici narodnih neprijatelja jer tako nešto ne bi bilo moguće da su tu kosti žrtava koje su streljali fašisti. Šezdesetih godina prošlog veka prilikom proširenja fabričkog kruga Zastave na ovom mestu sagrađen je i parking, iako se znalo za masovnu grobnicu. Kada je tom prilikom poravnjavan teren oštećen je površinski sloj masovne grobnice pa se na njenom početku nalaze samo delovi skeleta, dok su se na većoj dubini ukazali kompletni skeleti in-situ. Lica su, prema dosadašnjim nalazima, ubijena na tom mestu i nije bilo prebacivanja tela žrtava kako se spekulisalo, budući da su nađene i čaure metaka koje to potvrđuju.

Dalja arhivska i terenska istraživanja na popisu žrtava kao i utvrđivanju lokacija tajnih grobnica nastavljaju se tokom 2013. godine. 
Momčilo Pavlović

Srđan Cvetković

\section{THE REPORT OF THE STATE COMMISSION`S RESEARCH OF THE KILLED PERSONS AFTER 12 SEPTEMBER 1944}

\section{Summary}

The article provides an intersection and analysis of former researches of the State Commission for Secret Graves, dealing with the lists of persons as well as probing the locations of „secret graves“. It also analyses political, national, gender, age and social structure of nearly 37000 killed and missing persons recorded until 6th December 2012. 